\title{
Trends in Antarctic Geopotential Height and Temperature: A Comparison between Radiosonde and NCEP-NCAR Reanalysis Data
}

\author{
GARETh J. MARShall \\ British Antarctic Survey, Natural Environment Research Council, Cambridge, United Kingdom
}

(Manuscript received 14 September 2000, in final form 3 September 2001)

ABSTRACT

\begin{abstract}
A comparison of 40-yr (1960-99) trends in Antarctic geopotential height and temperature from quality controlled radiosonde observations and NCEP-NCAR reanalysis (NNR) data is undertaken. Observations from four Antarctic stations-having sufficiently long-term and consistent datasets-at four pressure levels $(850,500,300$, and $100 \mathrm{hPa}$ ) are utilized. The NNR reveals substantial negative trends in tropospheric geopotential height at high southern latitudes with no significant trends seen in the lower stratosphere above Antarctica. In contrast, observations indicate only minor negative trends in tropospheric height, while statistically significant decreases in height in the lower stratosphere have occurred over East Antarctica. However, both NNR and observations show a consistent, significant warming $\left(\sim 1^{\circ} \mathrm{C}\right)$ in the lower troposphere $(>500 \mathrm{hPa})$ above coastal Antarctica. At higher altitudes, trends derived from the two datasets diverge; the NNR fails to capture the marked cooling in the lower stratosphere associated with seasonal ozone loss. Differences in the trends are principally caused by NNR errors prior to the assimilation of satellite sounder data, which coincides with significant jumps in NNR upper-air temperatures. A rapid drop in NNR tropospheric geopotential height across East Antarctica as recently as 1993 is traced to the introduction of automatic weather stations in the region. Errors in the model height of these surface pressure data cause a significant climate jump in the NNR not observed in comparable models. Such spurious jumps considerably diminish the usefulness of the NNR for climate change studies in Antarctica.
\end{abstract}

\section{Introduction}

Observed modifications in the vertical temperature structure of the atmosphere have been proposed as a primary indicator of climate change. Most general circulation models (GCMs) predict both a midtropospheric warming and a stratospheric cooling associated with an increase in atmospheric "greenhouse" gases: these changes will be more evident against a background of natural variability than any surface warming (Barnett and Schlesinger 1987). Therefore, observations of atmospheric temperatures are vital for testing the hypothesis of an anthropogenically induced climate change-by comparison with appropriately forced GCMs (e.g., Santer et al. 1996; Tett et al. 1996).

Radiosonde data remain the primary source for monitoring changes in upper-air parameters. They have several advantages in determining temperature as compared with satellite-derived data from the microwave sounding unit (MSU): (i) the time series of data from radiosondes are far longer than those of the MSU, which only begin in 1979; (ii) the MSU has a much poorer vertical resolution; and (iii) changes in tropospheric humidity, sat-

Corresponding author address: Dr. Gareth J. Marshall, British Antarctic Survey, Natural Environmental Research Council, High Cross, Madingley Rd., Cambridge, CB3 OET, United Kingdom.

E-mail: gjma@pcmail.nbs.ac.uk ellite orbits, and intersatellite instrument characteristics all impact the relative accuracy of the MSU instruments and compromise their capability to detect small changes in atmospheric thermal structure (e.g., Christy 1995; Gaffen 1998; Hurrell and Trenberth 1998; Wentz and Schabel 1998). The principal problem with utilizing radiosonde data to determine global temperature changes lies with its inhomogeneous distribution across the earth's surface. Thus, in past studies that have utilized radiosonde time series to produce estimates of global changes in atmospheric temperatures (e.g., Angell 1988; Oort and Liu 1993; Parker et al. 1997; Gaffen et al. 2000) there has been a necessary "trade-off" in deciding the exact network to use, between trying to achieve as wide a spatial distribution as possible without sacrificing too much accuracy due to missing/short/unreliable data records. Wallis (1998) attempted to provide an optimum network of global radiosonde data, although this will clearly vary with application.

A third source of "observed" upper-air data are the reanalysis projects, in which an historical archive of meteorological data are assimilated into a consistent, state-of-the-art numerical forecast model; thus, there are no spurious climate changes introduced through updates to the model code. Such reanalyses have been compared to both radiosonde and satellite data, both of which they assimilate, on a global basis (Shah and Rind 1998; San- 
ter et al. 1999), in the Tropics (Randel et al. 2000) and in the polar stratospheres (Randel and Wu 1999).

This study focuses on a comparison of long-term changes in tropospheric and lower-stratospheric geopotential height and temperature over Antarctica from radiosonde observations and reanalysis data. Antarctica is a key region to examine for signs of global change because GCMs generally predict greater warming in the polar regions than elsewhere, due to the positive feedback between air temperature, ice extent (sea ice in particular), and albedo. Such warming signals in the lower troposphere have been observed in the Arctic (Kahl et al. 2001), together with contemporaneous oceanographic and surface circulation changes (Dickson 1999). Previous radiosonde studies differ in their findings with regard to tropospheric temperature trends at high southern latitudes (south of $60^{\circ} \mathrm{S}$ ). For example, Angell (1988) shows that the annual warming between 850 and $300 \mathrm{hPa}$ in this region was probably the largest anywhere on the planet between 1958 and 1987 (cf. his Fig. 6), whereas Oort and Liu (1993) show that from 1963 to 1989 the warming trend at this height was much greater in the Tropics (cf. their Fig. 7). Hence, markedly divergent conclusions can reached using different radiosonde networks, a problem examined in detail by Santer et al. (1999) and Gaffen et al. (2000). However, all studies are in agreement that the high southern latitudes have demonstrated the greatest decrease in lowerstratospheric temperatures, beginning in the early 1980s and believed to be principally due to the formation of the Antarctic ozone hole; see, for example, Jones and Shanklin (1995) and Randel and Wu (1999). Changes in geopotential height over Antarctica relative to the southern extratropics will alter the strength of the zonal westerly winds over the Southern Ocean and may reflect a shift in the phase of the main mode of Southern Hemisphere variability, the Antarctic oscillation (Thompson and Wallace 2000).

Due to the sparse nature of meteorological observations across Antarctica and upper-air data in particular, reanalyses are especially important for climate studies in this region (e.g., Hines et al. 2000). As they assimilate satellite data over the oceans they represent the best overall depiction of the state of the atmosphere at high southern latitudes. However, Bromwich et al. (2000) clearly demonstrated that for such calculations to be of use in Antarctic climate studies it is essential that the troposphere is represented as accurately as possible within the reanalyses.

In this study, radiosonde observations are compared directly against reanalysis output data at four standard levels: 850, 500, 300 (troposphere), and $100 \mathrm{hPa}$ (lower stratosphere). Note that occasionally in winter the Antarctic tropopause may lie below the $300-\mathrm{hPa}$ level but typically this is not the case and this pressure level is described as being part of the troposphere in this paper. Previously only short-term operational numerical analyses have been compared in detail against radiosonde data over Antarctica (Cullather et al. 1997). The National Centers for Environmental Prediction-National Center for Atmospheric Research (NCEP-NCAR) reanalysis (hereafter NNR) is currently the longest available, encompassing the period from 1948 to the present and thus includes the complete period of most of the upper-air records from Antarctica, many of which began in the International Geophysical Year of 1957/58. The long-term trends in this study are derived from the 40yr period spanning 1960-99.

This paper is presented in the following sections. In section 2 , the two types of monthly data examined in this study are described, including an account of the radiosonde quality control procedures employed. The long-term trends in geopotential height and temperature are considered in section 3, and differences between them are examined and accounted for. In section 4 a rapid drop in tropospheric geopotential height across East Antarctica observed in the NNR in 1993 is investigated in a detailed study to try to discover the causes behind this relatively recent, spurious climate jump. Radiosonde data from a number of additional stations are employed together with information regarding the number of observations available to the NNR and comparisons with different operational analyses. Finally, in section 5, the principal conclusions from this study are summarized.

\section{Data}

\section{a. Radiosondes}

\section{1) DAta SOURCES}

Only four Antarctic stations were deemed to have sufficient data available for the analysis of long-term trends from 1960 to 1999; these are the Australian stations of Mawson, Davis, Casey, and the U.K. station at Halley (see Fig. 1). Unfortunately and somewhat surprisingly the Russian and U.S. data did not meet the strict criteria; a mean monthly value was calculated only if at least 10 data points existed for that month and any gap between observations was less than 5 days. There were too many months when this was not possiblefor example, at McMurdo station, only 224 out of a possible 480 monthly mean values of $100-\mathrm{hPa}$ geopotential height could be determined-to allow a reliable long-term trend to be calculated. Also note that three other stations are used for comparison as appropriate in section 4 (Fig. 1). In order to acquire as complete a dataset as possible data Australian and U.K. data were obtained from the appropriate national center. Radiosonde data from the other stations used and operated by other countries were not easily available. Therefore, what has become known as the "Parish dataset" (collated by T. Parish, University of Wyoming) was utilized: this encompasses all Antarctic stations from 1980 to 1993 - although the data from a given station are sometimes far from complete-and can be obtained from the 


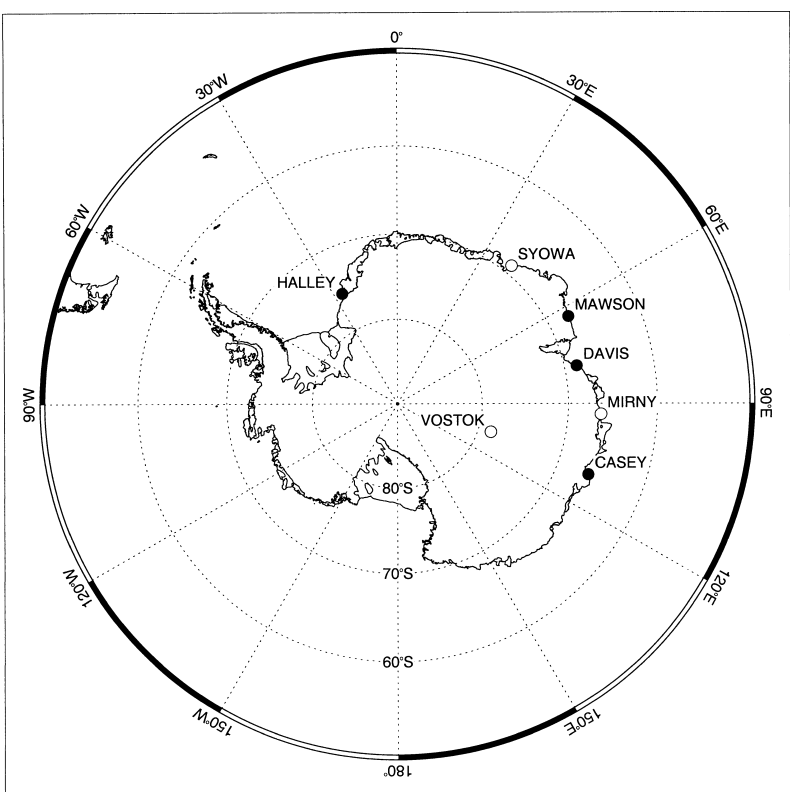

FIG. 1. Map showing the location of stations with radiosonde observations examined in this study. Black circles are the four stations where long-term trends are investigated. White circles are additional stations examined in an analysis of a problem in the NNR in 1993

Antarctic Meteorological Research Center. From 1988 onward this dataset was supplemented with data extracted from the World Meteorological Organization's (WMO) TEMP bulletins on the Global Telecommunication System (GTS) received by the U.K. Met. Office (UKMO).

Metadata for the three Australian stations were obtained from the Comprehensive Aerological Research Dataset (CARDS) Web site (http://www.ncdc.noaa.gov/ cards/cards_homepage.html), while for Halley complete records exist at the British Antarctic Survey (BAS). The CARDS metadata suggest that six different types of radiosonde were used at the Australian stations between 1960 and 1999, and that the three stations did not necessarily change radiosonde types simultaneously. At Halley, five types of radiosonde have been employed since 1960 and these are summarized in Table 1. In addition, there have been alterations to the data-processing algorithms used at all four stations as these are being continually updated as new equipment becomes available and improved by the various radiosonde manufacturers.

\section{2) QuAlity CONTROL}

Many studies of upper-air data have assumed the radiosonde dataset to be temporally homogeneous. However, there are several reasons why such an assumption may not necessarily be valid; for example, changes in radiosonde type, as demonstrated by the four Antarctic stations in this study (see Gaffen 1994; Gaffen et al. 2000; Parker and Cox 1995 for more details). Adjust-
TABLE 1. A history of radiosonde instruments used at Halley, 1960-99 (source: British Antarctic Survey).

\begin{tabular}{ll}
\hline \hline Time period & \multicolumn{1}{c}{ Radiosonde type } \\
\hline $1960-71$ & Whiteley Mk I \\
$1971-75$ & Graw M60 \\
$1975-84$ & VIZ type 1207 \& 1395 \\
$1984-92$ & Vaisala RS 80 \\
$1992-2000$ & Intellisonde type 4A \& 5A \\
$2000+$ & Vaisala RS 80 \\
\hline
\end{tabular}

ments for these systematic errors (bias) can be achieved through comparisons against neighboring stations, operational model analyses (if these can be trusted), international radiosonde intercomparisons (e.g., Nash and Schmidlin 1987) and by modeling the thermodynamics of the radiosonde instruments themselves (e.g., Luers and Eskridge 1998). In addition, data derived from the TEMP messages via the GTS will acquire occasional random and potentially very large errors during the transmission process: incorrect coding procedures can be employed at the originating station or data may be miskeyed. Thus it is important that radiosonde observations be quality controlled.

The quality control process described here uses techniques from the fields of resistant, robust, and nonparametric statistics (Lanzante 1996). These have the important advantage over parametric techniques of being less affected by the outliers that may exist in radiosonde time series as a result of the random errors described above. Only an outline of the procedures is given here, see Lanzante $(1996,1998)$ for a more detailed account of the statistical theory and the explicit equations employed.

\section{(i) Removal of random errors: The biweight mean and standard deviation}

To account for the annual cycles in geopotential height and temperature this element of the quality control was undertaken by segregating the radiosonde time series of each station into individual calendar months. For each month the biweight mean and standard deviation were estimated; these biweight estimates are weighted averages with observations having a nonlinearly decreasing weight away from the distribution center. Beyond a certain distance from the center the extreme outliers can be censored (weighting is zero): in this study that distance was set to five standard deviations from the mean. Preliminary estimates of the median and median absolute deviation were then used to determine the weights given to each observation. Once the weights of the outliers had been adjusted to alter their influence on the statistics the biweight mean and standard deviation were recalculated. Finally, using these two parameters, all data further than three standard deviations from the mean were removed. For the 32 various combinations examined for long-term trends ( 4 stations, 4 pressure levels, and 2 parameters) this pro- 


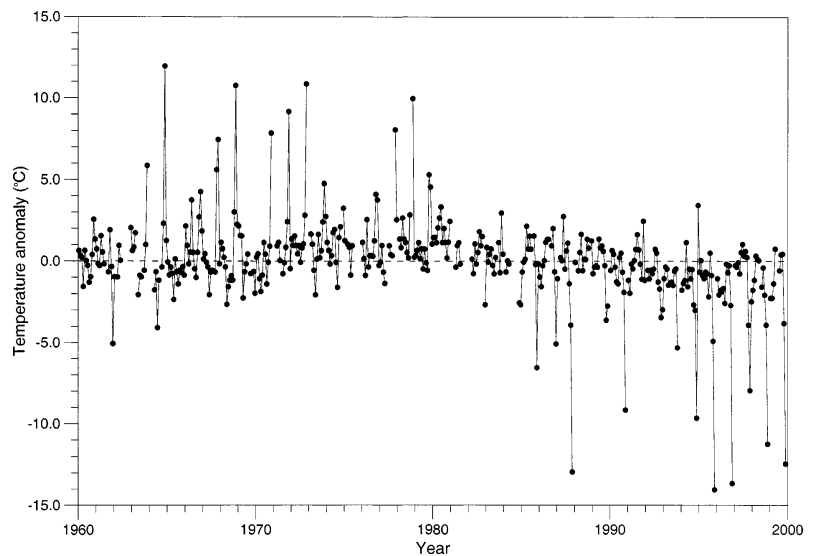

FIG. 2. Monthly 100-hPa temperature anomaly at Halley station.

cedure removed between $0.3 \%$ and $1.5 \%$ of the observations.

\section{(ii) Identification and removal of systematic errors: The change-point test}

The change-point procedure used here (Lanzante 1996) is independent of external data sources. However, Gaffen et al. (2000) recommended the combined use of historical metadata and statistical methods as best practice, to use the former to ensure there is some physical basis for any change points found by the latter. The test determines whether a discontinuity (a significant change in the median) has occurred and, if so, when. Lanzante (1996) proposed an iterative method whereby more than one change point in a time series could be identified. This nonparametric test calculates a statistic for each data point based on the sum of the ranks of the data from the start of the time series to that point. The point where this sum is most different to the expected sum is considered a potential change point. It is then added to a list of such points, which also includes the first and last points in the time series: this list is used to define change-point segments. The median is computed for each segment and subtracted to produce an adjusted series that is resubmitted to the change-point test in the subsequent iteration. Adjustment continues until the significance of a test statistic associated with the new change point falls below some critical threshold. This statistic is the discontinuity signal-to-noise ratio, which expresses the magnitude of the discontinuity in terms of the ratio of the variance associated with the shift in median between adjacent change-point segments relative to the background variability in each segment.

The 32 combinations were examined for significant change points (those where the discontinuity signal-tonoise ratio exceeded 0.10). Despite the numerous equipment changes, only four time series combinations revealed such a change point, of which there was only one. These were all associated with 100-hPa temperatures and all occurred in the early 1980s. Using the
TABLE 2. Comparison of monthly radiosonde observations and NCEP-NCAR reanalysis data for 1960-99. Data shown are the number of months for which a reliable mean can be determined (see text), the mean difference (NNR - observations) and the root-mean-square difference between the two datasets.

\begin{tabular}{|c|c|c|c|c|c|c|}
\hline \multirow[b]{2}{*}{ Station } & \multicolumn{3}{|c|}{ Geopotential height (dm) } & \multicolumn{3}{|c|}{ Temperature $\left({ }^{\circ} \mathrm{C}\right)$} \\
\hline & $n$ & $x \Delta$ & $\operatorname{rms} \Delta$ & $n$ & $x \Delta$ & $\operatorname{rms} \Delta$ \\
\hline & & & $850 \mathrm{hPa}$ & & & \\
\hline Mawson & 475 & 2.18 & 3.51 & 476 & -1.21 & 2.63 \\
\hline Davis & 413 & 1.81 & 2.91 & 414 & -0.18 & 1.77 \\
\hline Casey & 473 & 2.11 & 3.51 & 473 & -1.92 & 3.50 \\
\hline Halley & 453 & 1.71 & $\begin{array}{c}2.74 \\
500 \mathrm{hPa}\end{array}$ & 452 & -2.35 & 3.07 \\
\hline Mawson & 473 & 1.44 & 2.71 & 476 & -0.10 & 0.74 \\
\hline Davis & 413 & 1.21 & 2.35 & 414 & -0.11 & 0.66 \\
\hline Casey & 471 & 1.29 & 2.93 & 473 & -0.13 & 0.69 \\
\hline Halley & 453 & -0.03 & $\begin{array}{c}2.55 \\
300 \mathrm{hPa}\end{array}$ & 452 & -0.31 & 0.73 \\
\hline Mawson & 473 & 1.89 & 2.93 & 476 & 1.04 & 1.45 \\
\hline Davis & 413 & 1.74 & 2.73 & 415 & 1.14 & 1.55 \\
\hline Casey & 470 & 1.60 & 3.19 & 472 & 0.92 & 1.49 \\
\hline Halley & 452 & 0.97 & $\begin{array}{c}2.82 \\
100 \mathrm{hPa}\end{array}$ & 452 & 1.89 & 2.27 \\
\hline Mawson & 439 & -0.77 & 5.06 & 436 & -0.99 & 2.21 \\
\hline Davis & 380 & 0.19 & 5.15 & 377 & -0.47 & 1.95 \\
\hline Casey & 456 & -1.80 & 5.33 & 453 & -1.32 & 2.72 \\
\hline Halley & 426 & 1.60 & 4.42 & 406 & -0.56 & 1.79 \\
\hline
\end{tabular}

Halley data as an example, Fig. 2 demonstrates the reason for this. The majority of the monthly $100-\mathrm{hPa}$ temperature anomalies are less than $2^{\circ} \mathrm{C}$. However, prior to (after) $\sim 1982$ there are a series of large positive (negative) anomalies, all occurring in November, with smaller anomalies in October. The cause of this temperature decline is the depletion of ozone in this region (the Antarctic ozone hole) that began in the early 1980s. The change-point procedure found the switch from the positive to the negative November $100-\mathrm{hPa}$ temperature anomalies-in the case of Halley this changed the median anomaly from $0.41^{\circ} \mathrm{C}$ before the change point to $-0.65^{\circ} \mathrm{C}$ after it-and therefore this change point reflects real "climate change" rather than a systematic error associated with changing observing practice. Lanzante (1986) does state that the value of the discontinuity signal-to-noise ratio will vary with application. However, the fact that this parameter did not exceed 0.10 in any of the other combinations provides further evidence that there are no systematic errors in any of the radiosonde time series examined for the long-term trends.

\section{(iii) Production of a reliable monthly mean}

The last component of the quality control is to produce a monthly mean figure. Following the procedures of the Met Office (1979), a mean monthly value was calculated if at least 10 data points existed for that month and that any gap between observations was less than 5 days. The numbers of monthly values produced for a given station/height/variable combination are given in Table 2; the lower figures at Davis are because this 


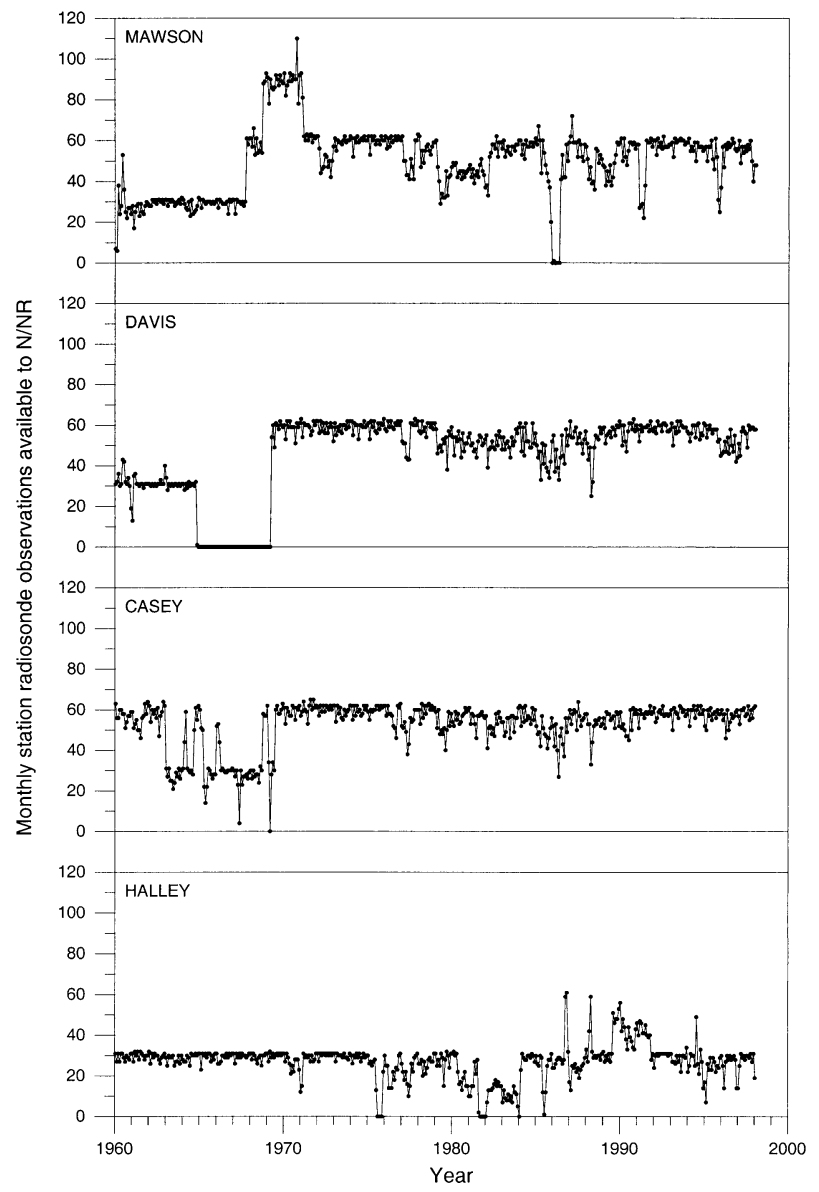

FIG. 3. Monthly radiosonde observations available to the NNR from Mawson, Davis, Casey, and Halley stations.

station was closed between November 1964 and February 1969.

\section{b. NCEP-NCAR reanalysis}

The NNR project is described in detail by Kalnay et al. (1996). In this section only the main features of the reanalysis model and those that specifically impact the geopotential height and temperature fields are outlined. In addition, the numbers of radiosonde observations available to the NNR from the four stations used to examine long-term trends are discussed.

The reanalysis model is based on the NCEP operational model of 10 January 1995 with a reduced horizontal resolution of T62 $(\sim 210 \mathrm{~km})$ and 28 vertical levels. As the reanalysis uses data types additional to the operational analysis a more complex quality control system was introduced. A global radiosonde database, provided by NCAR was the principal resource for upperair data, supplemented by various national archives. Satellite sounder data were first assimilated into the reanalysis in March 1975 (Jenne 2000) but principally comprise the Television Infrared Observational Satellite
(TIROS) Operational Vertical Sounder (TOVS) data from 1979 onward: over the Southern Ocean these were the first systematic observations available to the reanalysis and led to a major improvement in Southern Hemisphere forecasts (Kistler and Kalnay 2000). These data are used to derive the vertical temperature profile but are only employed below $100 \mathrm{hPa}$ over the ocean and only have significant weight when radiosonde data are lacking (Basist and Chelliah 1997). However, both Casey and Halley lie outside the NNR land-sea mask. It should also be noted that satellite retrieval algorithms from TOVS soundings are continually being improved and these changes will be present in the reanalysis. In addition, surface pressure is assimilated from many ground stations and this may impact the reanalysis vertical temperature profile in the lower troposphere over the Antarctic interior because of the high surface elevation there, which exceeds $4 \mathrm{~km}$ at its highest point (see section 4).

Both geopotential height and temperature at the chosen standard levels are described as class A output variables (Kalnay et al. 1996), that is they are strongly influenced by observed data. Other studies have demonstrated that prior to meteorological data becoming available on the GTS in 1967 many synoptic data from Antarctic stations are missing from the NNR (Hines et al. 2000; Marshall and Harangozo 2000). The number of monthly observations in each $2.5^{\circ} \times 2.5^{\circ}$ lat-lon box is obtainable and, because of the sparse distribution of Antarctic radiosonde data, the actual number of observations from a particular station can be derived from these. The quantity of monthly data reaching the NNR from the four stations examined is shown in Fig. 3. This shows that typically, from 1970 onward, there are two daily radiosonde flights from the three Australian stations (as this is not always the case only the 0000 UTC data are used in this analysis). At Halley there is typically only one observation per day and when compared to the BAS archives the dataset is complete, with the months when fewer data were available being caused by circumstances other than GTS problems. Thus it appears likely that the complete datasets for these stations were made available to NCAR.

An additional potential problem with the NNR concerns the Australian pseudo-observations of sea level pressure (PAOBS) - the product of human analysts who estimate sea level pressure based on satellite data, conventional data, and time continuity - that were assimilated with a $180^{\circ}$-lon error between 1979 and 1992. Due to the sparse nature of data at high southern latitudes this had its greatest impact between $45^{\circ}$ and $60^{\circ} \mathrm{S}$ but with a decreasing influence thereafter toward the South Pole. However, it is not believed that this will impact the present study greatly because the significance of the errors declines rapidly from synoptic to monthly timescales (cf. http://wesley.wwb.noaa.gov/paobs/paobs_1.html). 


\section{Long-term trends}

\section{a. Statistical analysis methodology}

The significance of the linear long-term trends (calculated using least squares regression analysis), is computed from annual anomalies using the methodology outlined by Trenberth (1984). This accounts for the effects of autocorrelation by calculating the number of effectively independent samples for use in the subsequent Student's t-test for significance, rather than the number of observations themselves. However, when calculating the temporal trend of a single variable, the predictor value, time, is not random; therefore, when the time between independent samples is computed the residuals of the regression equation are used instead of the two independent time series (e.g., Smith et al. 1996). Confidence intervals for the trends are calculated at the 95\% level (von Storch and Zwiers 1999) with the degrees of freedom based on the number of independent samples. Note that using this methodology it is possible in some cases for trends to be statistically significant at below the $10 \%$ level without us being $95 \%$ confident that they are of a particular sign. To increase the number of annual data available to derive the 40-yr trends, a single month of data missing from a calendar year was estimated using a linear regression trend for that calendar month, provided at least $90 \%$ (36) of values existed.

When providing data equivalent to station observations from the reanalysis data the NNR fields were interpolated to the nearest $0.1^{\circ}$ in both latitude and longitude to the station position. A slight bias might have been introduced into the trends, especially at $100 \mathrm{hPa}$, because of the greater number of months when the criteria for a climatological mean are met in the more recent period. However, the exact nature of the bias will depend on the long-term trends in the data and has been assumed to be insignificant. Other potential causes of bias in the trends are discussed where appropriate.

Note that the radiosonde data are assumed to be closer to the "truth" than the NNR data and bias in the latter rather than the former are described. Nevertheless, it should be noted that the early radiosonde data did not have radiation corrections made to it while some adjustments were made to account for this factor in the NNR: therefore, the NNR might be closer to the truth in some cases. However, the advent of satellite sounder data significantly reduces the difference between the radiosonde data and NNR by affecting only the latter (see below suggesting that the reanalysis data contain the greater error during the early period). Moreover, no significant change points were found in the monthly radiosonde data series, indicating that any "missing" radiation corrections are of relatively small magnitude compared to the natural variability.

\section{b. Geopotential height}

1) DiFFERENCES BETWEEN RADIOSONDE OBSERVATIONS AND NNR DATA

The differences between the interpolated monthly radiosonde observations and NNR data in geopotential height at Mawson, Davis, Casey, and Halley are shown in Fig. 4. For each height and station combination the mean and rms difference are given in Table 2. At 850 $\mathrm{hPa}$ the NNR data are generally higher than the radiosonde observations at all four stations with the rms difference being markedly less at Halley and Davis. In the latter case this is because of the missing 1960s datathe station was closed-when the differences are generally greater than average. A significant improvement in these values occurs around 1970, in 1968 at Halley, for example (Fig. 4a). This is not coincident with either equipment changes (cf. Table 1) or an increase in radiosonde observations available to the NNR (Fig. 3). However, there was a significant increase in the number of synoptic reports in 1972 in the East Antarctic, which will influence the model $850-\mathrm{hPa}$ geopotential height in this area. Note the switch from a positive to a negative bias in the NNR at the three Australian stations in 1993 with a subsequent return toward the earlier bias-this feature is the subject of investigation in section 4 present throughout the troposphere and lower stratosphere (Figs. 4a-d). At 500 and 300 hPa (Figs. 4b and $4 \mathrm{c}$, respectively) the difference between reanalysis and observations shows a broadly similar picture to that at $850 \mathrm{hPa}$. However, Table 2 indicates that the reanalysis better represents the observations at $500 \mathrm{hPa}$, and to a lesser extent at $300 \mathrm{hPa}$, than at $850 \mathrm{hPa}$.

Cullather et al. (1997) examined the NCEP operational data against radiosonde observations for 198993 at a number of Antarctic stations, and their Table 2 has mean and rms difference values of geopotential height for Casey and Halley at $500 \mathrm{hPa}$. For Casey, the values of Cullather et al. (and equivalent values in this study) of mean and rms difference are $-0.91(0.53 \mathrm{dm})$ and $3.15 \mathrm{dm}(1.98 \mathrm{dm})$, respectively, and for Halley they are $-0.44(-1.90 \mathrm{dm})$ and $1.82 \mathrm{dm}(2.48 \mathrm{dm})$, respectively. It should be remembered that the radiosonde observations to which the operational and reanalysis data are being compared might not be exactly the same. In addition, the interpolation procedures used in the two studies differ in that Cullather et al. (1997) use the grid point closest to the station for comparison rather than interpolating the model field. Bearing in mind these caveats, it appears that the NNR is superior to the NCEP operational analyses in representing 500$\mathrm{hPa}$ geopotential height at Casey but is less good at Halley.

The time series of monthly differences in geopotential height at $100 \mathrm{hPa}$ (Fig. 4d) are dissimilar from lower altitudes. This corroborates the findings of Mo et al. (1995); they undertook a study of the effect of satellite data into the reanalysis assimilation scheme and showed 

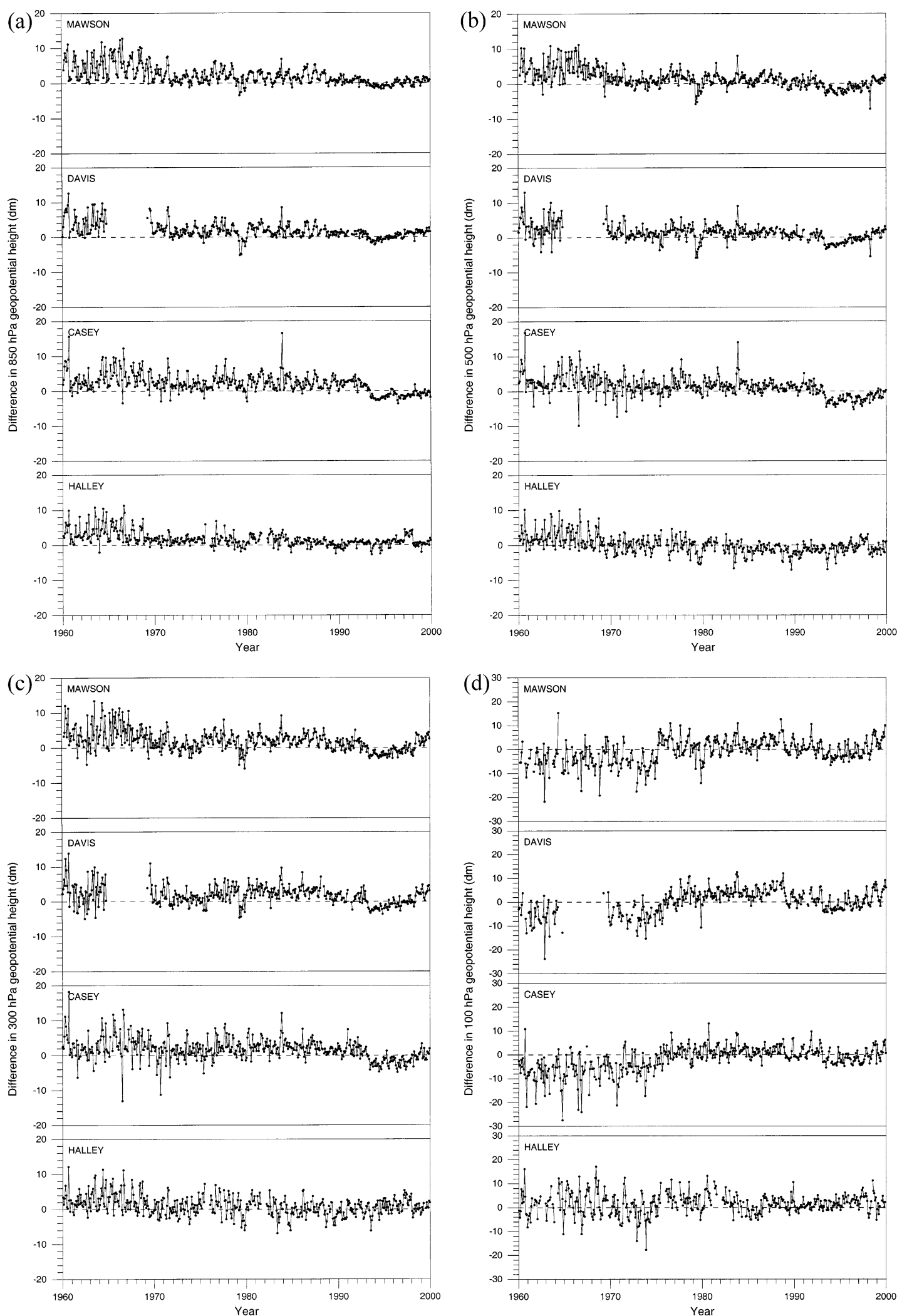

FIG. 4. The difference in monthly geopotential height between NNR data and radiosonde observations at four Antarctic stations between 1960 and 1999 at (a) 850, (b) 500, (c) 300, and (d) $100 \mathrm{hPa}$. Note the change in $y$-axis scale in Fig. 4d. 
TABLE 3. Mean annual trends in geopotential height at four heights for four Antarctic stations during 1960-99 as derived from radiosonde observations and NNR data. The 95\% confidence intervals of the trend are given in addition to the trend itself. RAOBS $n$ is the number of complete years available to calculate the trend from the radiosonde observations. Trends significant at the $10 \%$ level and below are underlined. If the confidence intervals do not overlap then the trends are considered significantly different. Units are in meters.

\begin{tabular}{|c|c|c|c|c|}
\hline Station & RAOBS & RAOBS $n$ & NNR & Different? \\
\hline & & $850 \mathrm{hPa}$ & & \\
\hline Mawson & $-0.4576+0.4384$ & 40 & $-1.8226 \pm 0.6203$ & $\mathrm{Y}$ \\
\hline Davis & $-0.4923 \pm 0.6959$ & 33 & $-1.7129 \pm 0.6479$ & $\mathrm{~N}$ \\
\hline Casey & $-0.3015 \pm 0.5625$ & 40 & $-1.5995 \pm 0.7837$ & $\mathrm{~N}$ \\
\hline \multirow[t]{2}{*}{ Halley } & $-0.4166 \pm 0.5931$ & 38 & $-1.2982 \pm 0.5222$ & $\mathrm{~N}$ \\
\hline & & $500 \mathrm{hPa}$ & & \\
\hline Mawson & $-0.2469 \pm 0.6416$ & 40 & $-1.6020 \pm 0.7364$ & $\mathrm{~N}$ \\
\hline Davis & $-0.5532 \pm 0.9786$ & 33 & $\overline{-1.5596 \pm 0.8195}$ & $\mathrm{~N}$ \\
\hline Casey & $-0.0787 \pm 0.7901$ & 40 & $-1.4105 \pm 0.9063$ & $\mathrm{~N}$ \\
\hline \multirow[t]{2}{*}{ Halley } & $+0.0495 \pm 0.8781$ & 38 & $-0.9128 \pm 0.6452$ & $\mathrm{~N}$ \\
\hline & & $300 \mathrm{hPa}$ & & \\
\hline Mawson & $-0.1026 \pm 0.8992$ & 40 & $-1.1830 \pm 0.9251$ & $\mathrm{~N}$ \\
\hline Davis & $-0.5166 \pm 1.2153$ & 33 & $\overline{-1.2257 \pm 1.0274}$ & $\mathrm{~N}$ \\
\hline Casey & $-0.0013 \pm 1.0003$ & 40 & $\overline{-0.9912 \pm 1.0646}$ & $\mathrm{~N}$ \\
\hline \multirow[t]{2}{*}{ Halley } & $+0.3246 \pm 0.9211$ & 38 & $-0.2857 \pm 0.6927$ & $\mathrm{~N}$ \\
\hline & & $100 \mathrm{hPa}$ & & \\
\hline Mawson & $-2.1990 \pm 1.8612$ & 32 & $-0.2302 \pm 1.9405$ & $\mathrm{~N}$ \\
\hline Davis & $-3.0711 \pm 2.7717$ & 26 & $-0.2722 \pm 1.9409$ & $\mathrm{~N}$ \\
\hline Casey & $\overline{-1.9353 \pm 2.0559}$ & 36 & $+0.3569 \pm 1.9064$ & $\mathrm{~N}$ \\
\hline Halley & $-0.9773 \pm 2.0317$ & 31 & $-0.5893 \pm 1.6898$ & $\mathrm{~N}$ \\
\hline
\end{tabular}

that such data had its greatest impact in the Antarctic stratosphere. At Mawson and Casey the mean difference is positive while at Davis and Halley it is negative (Table 2). Prior to approximately 1975 the NNR has a very negative bias at the Australian stations, typically about $8 \mathrm{dm}$. There is then a change in this bias such that it becomes slightly positive and the variability declines markedly - the latter observation also applies to the Halley data. The most likely reason for this change appears to be the introduction of satellite sounder data in 1975 (Jenne 2000) despite the volume of such data in this region being relatively small prior to the assimilation of TOVS in 1979 (cf. Fig. 1 of Kistler and Kalnay 2000).

\section{2) COMPARISON OF 40-YR TRENDS IN RADIOSONDE OBSERVATIONS AND NNR DATA}

The 40-yr trends in geopotential height from 1960 to 1999 at the four Antarctic stations from both the radiosonde observations and NNR data are summarized in Table 3. In the troposphere there is only one statistically significant trend (at the $10 \%$ level or below), at Mawson at $850 \mathrm{hPa}$. However, in the NNR data the opposite is true, with just one trend that is not statistically significant. In all cases, the reanalysis trends are much more negative than their equivalents derived from the radiosonde data. However, due to the large confidence intervals associated with the trends there is only one instance when the two trends can be considered significantly different: somewhat oddly this is at Mawson at $850 \mathrm{hPa}$, the only instance where both types of data demonstrate a statistically significant trend. In many cases the NNR trends are an order of magnitude greater than their radiosonde equivalents while at Halley at both
500 and $300 \mathrm{hPa}$ the sign of the trend is opposed. Figures $4 \mathrm{a}-\mathrm{c}$ reveal that the too strongly negative trends in the reanalysis data are principally a function of the large positive bias during the 1960s and, to a lesser extent, the switch to a negative bias toward the end of the time period analyzed.

At $100 \mathrm{hPa}$ the three East Antarctic stations show a significant decrease in geopotential height from radiosonde observations. At Halley there is also a negative trend but it is smaller and not statistically significant; these trends are related to the temperature changes at this height, probably associated with ozone loss and are discussed further in section $2 c(2)$. The NNR data show three of the stations having a negative trend, with Casey being positive. At Mawson and Davis the trend is an order of magnitude smaller than that from the radiosonde observations but at Halley the NNR does better, the trend being less than a factor of 2 too small. Figure $4 \mathrm{~d}$ demonstrates that, as at tropospheric altitudes, it is the too low values in the reanalysis over the East Antarctic stations prior to the assimilation of satellite sounder data that is the underlying cause in the marked difference in trends.

\section{c. Temperature}

\section{1) DifFERENCES BETWEEN RADIOSONDE OBSERVATIONS AND NNR DATA}

The difference in temperature between the monthly radiosonde observations and interpolated NNR data at the four stations are shown in Fig. 5; the mean and rms difference are given in Table 2. At $850 \mathrm{hPa}$ the difference plots show a very clear annual cycle with the NNR 

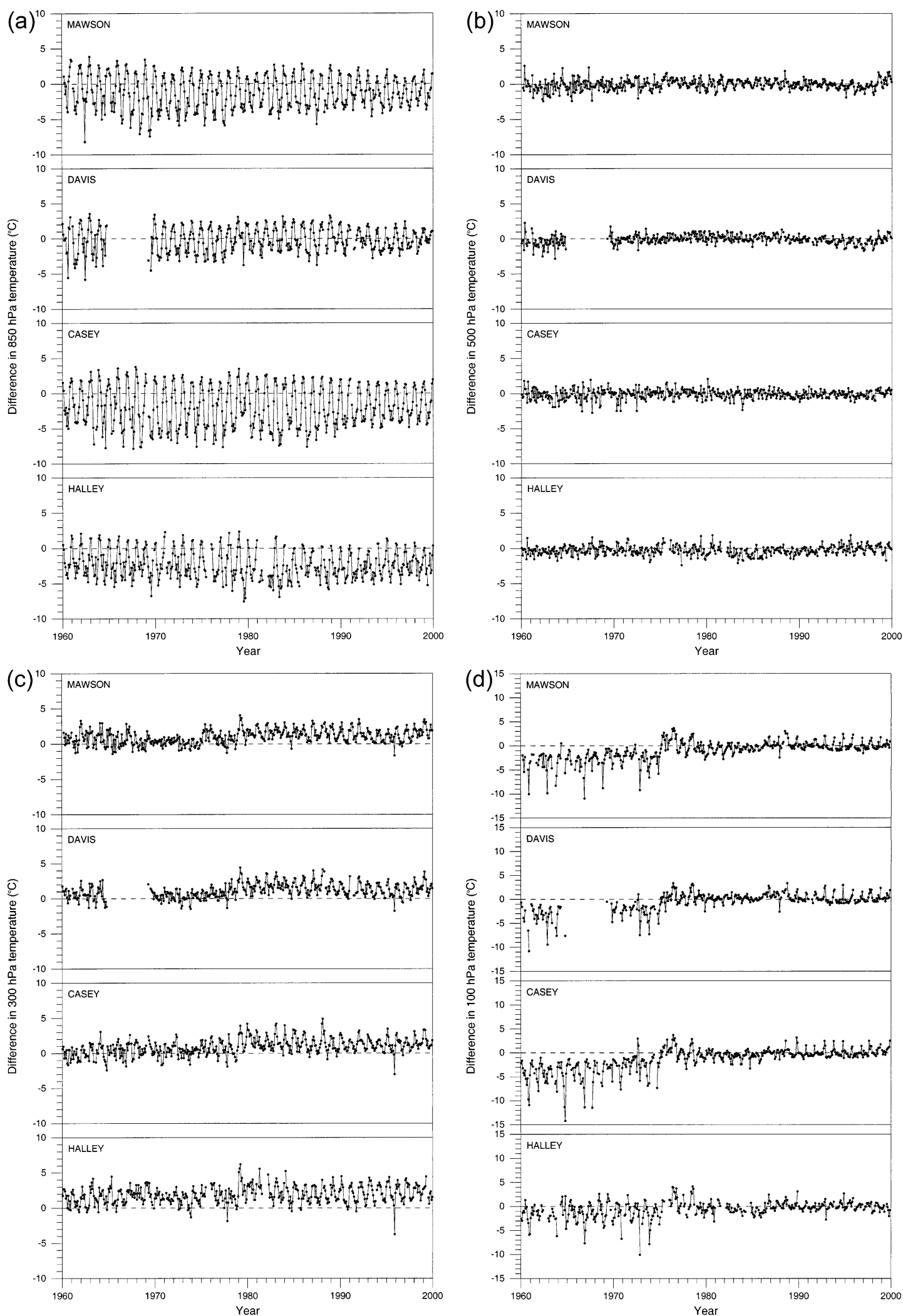

FIG. 5. The difference in monthly temperature between NNR data and radiosonde observations at four Antarctic stations between 1960 and 1999 at (a) 850, (b) 500, (c) 300, and (d) $100 \mathrm{hPa}$. 


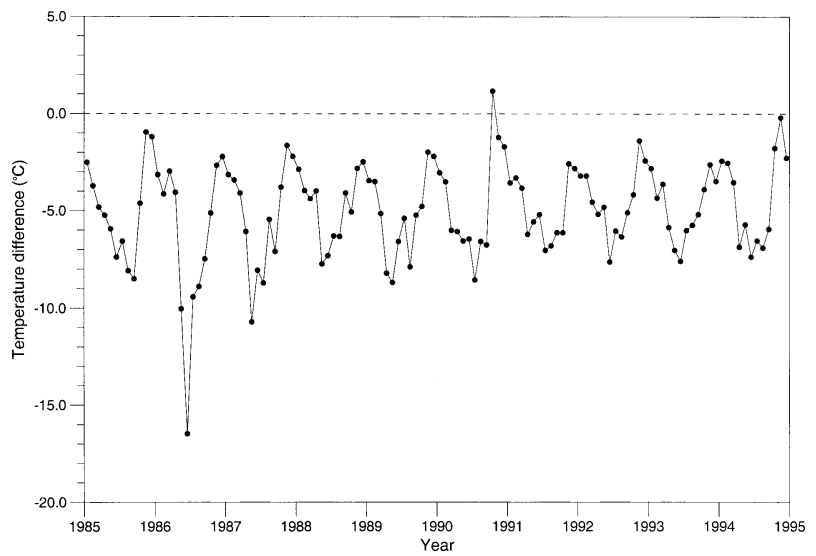

FIG. 6. The difference in monthly near-surface temperature between the NNR and synoptic observations at Casey for 1985-94.

data having their largest positive (negative) bias in summer (winter). The magnitude of the winter bias is greater than the summer bias (cf. the mean difference values in Table 2), with the difference largest at Casey where typically the maximum winter (summer) bias is $7^{\circ} \mathrm{C}$ $\left(2^{\circ} \mathrm{C}\right)$. There are no clear and consistent changes in the magnitude of this difference cycle through time, with the introduction of satellite sounder data in the 1970s having no significant impact. At $500 \mathrm{hPa}$ (Fig. 5b) the annual cycle has almost disappeared, suggesting that the problem may well be related to the model parameterization of physical processes at or near the surface, which are of fundamental importance in forcing the regional atmospheric flow in Antarctica (Parish 1988). As evidence for this hypothesis, Fig. 6 shows the difference in monthly near-surface temperatures between the NNR and synoptic observations at Casey for 1985-94: the reanalysis data are 2-m temperatures-which is a class $\mathrm{B}$ variable meaning that although directly affected by observational data, the model also exerts a very strong influence (Kalnay et al. 1996) — and the Casey observations are from J. Jacka, Antarctic Cooperative Research Centre, Australia. The near-surface temperatures demonstrate an annual cycle with similar amplitude to that at $850 \mathrm{hPa}$, although actual temperature differences are about $4^{\circ} \mathrm{C}$ smaller. Hines et al. (1999) found that in general reanalysis errors in the two sides of the NNR energy balance equation tended to cancel during the polar day. However, latent heat flux during spring and especially winter is too large, by greater than an order of magnitude in winter; in the period examined (July 1994) this error accounted for $87 \%$ of the deficit of 5.1 $\mathrm{W} \mathrm{m} \mathrm{m}^{-2}$. Thus, the analysis by Hines et al. (1999) offers an explanation for the observed annual cycle in NNR bias at $850 \mathrm{hPa}$.

At $500 \mathrm{hPa}$ the rms difference is significantly reduced from that at the lower altitude at all four stations. Again the introduction of the satellite sounder data has no significant impact on the bias in the NNR. Table 2 of Cullather et al. (1997) has mean and rms difference values of temperature for Casey and Halley at $500 \mathrm{hPa}$, derived from comparing the NCEP operational analyses against radiosonde observations for 1989-93. For Casey, the values of Cullather et al. (this study) of mean and rms difference are $-1.1^{\circ}\left(-0.25^{\circ} \mathrm{C}\right)$ and $2.0^{\circ} \mathrm{C}\left(0.52^{\circ} \mathrm{C}\right)$, respectively, and for Halley they are $-0.1^{\circ}\left(-0.36^{\circ} \mathrm{C}\right)$ and $1.0^{\circ} \mathrm{C}\left(0.61^{\circ} \mathrm{C}\right)$, respectively. Thus, the results are similar to geopotential height, in that the NNR is superior to the NCEP operational analyses in representing 500-hPa temperatures at Casey during this 5-yr period but is less good at Halley.

The monthly temperature differences at $300 \mathrm{hPa}$ are shown in Fig. 5c. At this altitude an annual cycle has appeared again, although its mean amplitude is only about one-third of that observed at $850 \mathrm{hPa}$ and is also less regular. At this level the mean difference is strongly positive at all four stations, varying from $\sim 1^{\circ}$ at Casey to nearly $2^{\circ} \mathrm{C}$ at Halley (Table 2). Unlike the two lower heights examined, at $300 \mathrm{hPa}$ the introduction of TOVS data in 1979 is clearly apparent. Figure 5c illustrates that the introduction of these data into the NNR model assimilation actually increases the positive bias shown by the reanalysis by about $2^{\circ} \mathrm{C}$. As the annual cycle of differences appears to be enhanced by the satellite sounder data, this suggests that the TOVS retrieval algorithms employed actually contain a seasonal bias in determining $300-\mathrm{hPa}$ temperature in the Antarctic region.

The impact of the introduction of satellite sounder data on NNR 100-hPa temperatures is very clear indeed (Fig. 5d). The improvement starts in the mid-1970s prior to the advent of TOVS and, as might be expected, coincides with an increase in the reanalysis geopotential height (cf. Fig. 4d). Thus it appears that even the small quantity of vertical temperature profile radiometer (VTPR) sounder data being assimilated into the NNR at this time had a huge impact at this altitude in this data sparse region: Mo et al. (1995) stated that satellite data have their greatest impact on atmospheric temperature above $200 \mathrm{hPa}$ and south of $60^{\circ} \mathrm{S}$ (cf. their Fig. $2 \mathrm{a})$ and this is confirmed by Plate 3 of Santer et al. (1999). These authors suggest that errors in the assimilation model's simulation of the lower stratosphere were also a contributing factor to the "overall model cold bias in the temperature field at high latitudes in the Southern Hemisphere ... a associated with errors in representation of the polar night jet" prior to the assimilation of satellite data. The introduction of this type of data greatly improves the accuracy of the NNR; for example, at Casey there were 35 months when the magnitude of the bias exceeded $5^{\circ} \mathrm{C}$ prior to 1976 and none thereafter. A further, small improvement appears to occur in 1979, coincident with the start of TOVS data, when the slight positive bias present in the NNR following the introduction of the earlier sounder data is reduced. From the mid-1980s onward an annual cycle can be seen whereby one or occasionally two months have a positive $2^{\circ} \mathrm{C}$ bias in the NNR. These months are 
TABLE 4. Mean annual trends in temperature at four heights for four Antarctic stations during 1960-99 as derived from radiosonde observations and NNR data. For an explanation of the figures see Table 3. Units are in ${ }^{\circ} \mathrm{C}$.

\begin{tabular}{|c|c|c|c|c|}
\hline Station & RAOBS & RAOBS $n$ & NNR & Different? \\
\hline \multicolumn{5}{|c|}{$850 \mathrm{hPa}$} \\
\hline Mawson & $+0.0153 \pm 0.0236$ & 40 & $+0.0101 \pm 0.0236$ & $\mathrm{~N}$ \\
\hline Davis & $-0.0032 \pm 0.0305$ & 33 & $+0.0170 \pm 0.0288$ & $\mathrm{~N}$ \\
\hline Casey & $+0.0268 \pm 0.0265$ & 40 & $+0.0312 \pm 0.0276$ & $\mathrm{~N}$ \\
\hline Halley & $\overline{+0.0347 \pm 0.0218}$ & 38 & $\overline{+0.0180 \pm 0.0192}$ & $\mathrm{~N}$ \\
\hline \multicolumn{5}{|c|}{$500 \mathrm{hPa}$} \\
\hline Mawson & $+0.0199 \pm 0.0189$ & 40 & $+0.0250 \pm 0.0183$ & $\mathrm{~N}$ \\
\hline Davis & $\overline{+0.0077 \pm 0.0244}$ & 34 & $\overline{+0.0143 \pm 0.0188}$ & $\mathrm{~N}$ \\
\hline Casey & $+0.0188 \pm 0.0194$ & 40 & $+0.0200 \pm 0.0188$ & $\mathrm{~N}$ \\
\hline Halley & $\overline{+0.0328 \pm 0.0209}$ & 38 & $\overline{+0.0388 \pm 0.0171}$ & $\mathrm{~N}$ \\
\hline \multicolumn{5}{|c|}{$300 \mathrm{hPa}$} \\
\hline Mawson & $+0.0159 \pm 0.0174$ & 40 & $+0.0439 \pm 0.0262$ & $\mathrm{~N}$ \\
\hline Davis & $\overline{+0.0103 \pm 0.0250}$ & 34 & $\overline{+0.0392 \pm 0.0244}$ & $\mathrm{~N}$ \\
\hline Casey & $+0.0057 \pm 0.0194$ & 40 & $\overline{+0.0460 \pm 0.0185}$ & $\mathrm{Y}$ \\
\hline Halley & $+0.0190 \pm 0.0240$ & 38 & $\overline{+0.0456 \pm 0.0382}$ & $\mathrm{~N}$ \\
\hline \multicolumn{5}{|c|}{$100 \mathrm{hPa}$} \\
\hline Mawson & $-0.1043 \pm 0.0434$ & 32 & $+0.0284 \pm 0.0978$ & $\mathrm{~N}$ \\
\hline Davis & $\overline{-0.1075 \pm 0.0672}$ & 27 & $+0.0332 \pm 0.0815$ & $\mathrm{~N}$ \\
\hline Casey & $\overline{-0.0801 \pm 0.0425}$ & 36 & $+0.0596 \pm 0.0627$ & $\mathrm{Y}$ \\
\hline Halley & $\overline{-0.0740 \pm 0.0781}$ & 30 & $\overline{-0.0355 \pm 0.1061}$ & $\mathrm{~N}$ \\
\hline
\end{tabular}

October and sometimes November and the bias is related to the significant loss of ozone during the austral spring at this altitude from the mid-1980s onward, the so-called Antarctic ozone hole.

\section{2) COMPARISON OF 40-YR TRENDS IN RADIOSONDE OBSERVATIONS AND NNR DATA}

The 40-yr upper-air temperature trends (1960-99) at the four Antarctic stations from both radiosonde observations and NNR data are summarized in Table 4. At $850 \mathrm{hPa}$ both the radiosonde and NNR data show statistically significant temperature increases at Casey and Halley and these trends are of similar magnitude in the two datasets. The trend at Halley from the radiosonde observations is equivalent to an increase of $1.4^{\circ} \mathrm{C}$ over the $40 \mathrm{yr}$. At $500 \mathrm{hPa}$ the trends in temperature demonstrated by the two datasets are remarkably similar, reflecting the excellent agreement between radiosonde observations and NNR at this height (cf. Fig. 5b). Note that Casey was the only Antarctic station with sufficient data to be utilized in the recent study of tropospheric and stratospheric temperature trends by Gaffen et al. (2000) based on monthly CLIMAT TEMP messages. Between 1959 and 1995 they found a warming at 700 $\mathrm{hPa}-0.015^{\circ} \mathrm{C} \mathrm{a}^{-1}$, significant at the $1 \%$ level-that lies between the trends at 850 and $500 \mathrm{hPa}$ derived from this study (cf. Table 4).

Agreement between observations and NNR is not so good at $300 \mathrm{hPa}$ however, although both datasets reveal temperature increases at all four stations, in the NNR the magnitude of the rate of warming is typically larger by a factor of 3 and at Casey the trends are even statistically significantly different. In the NNR all four stations have a significant warming trend while the radiosonde data indicate that this is only the case at Mawson.
The NNR generally shows an increase in the rate of warming with altitude in the troposphere whereas the radiosonde observations show a more mixed response (Table 4).

In the lower stratosphere at $100 \mathrm{hPa}$ the $40-\mathrm{yr}$ temperature trends in the radiosonde and NNR data are very different indeed. The observations all indicate a statistically significant cooling at this height, which has occurred principally in the last two decades [see Randel and Wu (1999) for examples from other Antarctic stations], and has been widely attributed to the radiative forcing due to losses in ozone and increases in carbon dioxide (e.g., Ramaswamy et al. 1996). However, more recently Forster and Shine (1999) have suggested that an as yet unexplained increase in stratospheric water vapor may have had an equally strong impact on stratospheric temperatures. In contrast, the reanalysis data have a warming trend at the East Antarctic stations (Table 4). Figure $5 d$ indicates that this divergence in the sign of the trends is principally a function of the far too low 100-Pa temperatures in the NNR prior to the introduction of satellite sounder data in 1975. More recently, reanalysis temperatures that are too warm in the austral spring following the formation of the Antarctic ozone hole in the mid-1980s have further enhanced the spurious positive trends. The next generation of reanalyses will address this problem by including a three-dimensional ozone field coupled to atmospheric dynamics (Uppala et al. 2000).

A potential bias in the radiosonde stratospheric temperature trends is due to the fact that balloons tend to burst with greater frequency at higher altitudes when temperatures are colder (Parker and Cox 1995). Thus we might expect a bias toward warmer temperatures and if the magnitude of this bias varied through time-if improved equipment meant fewer balloon bursts, for 
TABLE 5. The proportion of quality controlled radiosonde observations at $500 \mathrm{hPa}$ that is also available at $100 \mathrm{hPa}$.

\begin{tabular}{llcc}
\hline \hline Station & \multicolumn{1}{c}{ Season(s) } & $1960-79$ & $1980-99$ \\
\hline Casey & Winter (JJA) & $87 \%$ & $97 \%$ \\
& Spring-autumn & $72 \%$ & $94 \%$ \\
Halley & Winter (JJA) & $81 \%$ & $93 \%$ \\
& Spring-autumn & $80 \%$ & $82 \%$ \\
\hline
\end{tabular}

example-then this would cause a bias in the trend too. To investigate qualitatively whether such a bias may exist in the 100-hPa temperature trends examined in the current study, observation counts of the quality controlled data from Casey (as representative of the Australian stations) and Halley were examined. The proportion of observations available at $100 \mathrm{hPa}$ as a percentage of those at $500 \mathrm{hPa}$ was calculated separately for winter June-July-August (JJA) and the other nine months for both 1960-79 and 1980-99; results are given in Table 5. Interestingly, we can see that any bias introduced by fewer data available at $100 \mathrm{hPa}$ during winter will be of opposite sign at the two stations. At Casey there are proportionately significantly fewer observations at $100 \mathrm{hPa}$ in winter compared to the other nine months during the first half of the time series than during the second, which will introduce a cooling bias to the data. However, at Halley this position is reversed, so there will be a bias toward a warming. Both stations demonstrate similar long-term cooling trends at $100 \mathrm{hPa}$ (cf. Table 4) so any bias is deemed to be sufficiently small not to significantly impact the results.

\section{Investigation of the rapid drop in tropospheric geopotential height across east Antarctica in 1993 demonstrated by the NCEP-NCAR reanalysis}

The rapid decrease in the difference in tropospheric geopotential height between radiosonde observations and the NNR in 1993 - as seen in data from the three Australian stations at the $300-\mathrm{hPa}$ level and below but not at Halley (cf. Figs. 4a-c) - is a significant feature and warrants further investigation to explain its cause since it postdates the introduction of satellite sounder data (hereafter it will be referred to as the "1993 feature"). It is also observed at a number of other stations not operated by the Australians, such as Syowa and Mirny (Fig. 7). By comparing available radiosonde observations with the NNR data, the longitudinal region over which this feature is apparent extends from at least Syowa $\left(40^{\circ} \mathrm{E}\right)$ to Casey $\left(110^{\circ} \mathrm{E}\right)$. In Fig. 7 , which shows the difference in geopotential height between radiosonde observations and analysis at $500 \mathrm{hPa}$, the NNR data are compared against operational analyses from the Australian Bureau of Meteorology (AUST) and the UKMO for the period 1985-99. The European Centre for Medium-Range Weather Forecasts (ECMWF) data were not examined because of the known problems with

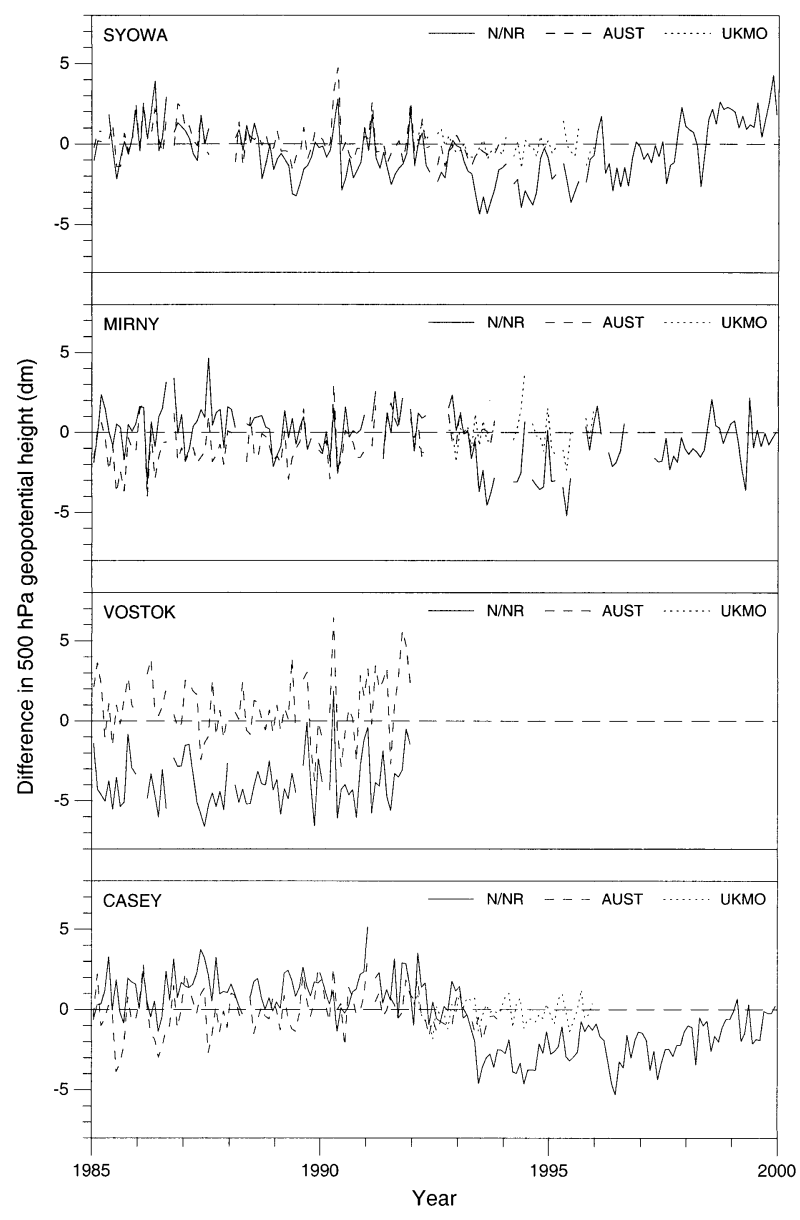

FIG. 7. Comparison of 500-hPa geopotential height differences between radiosonde observations and data from three analysis schemes at four East Antarctic stations. The analyses are those of the NNR, AUST, and the Met Office.

station heights over East Antarctica, at Vostok (Bromwich et al. 2000), Dome C (P. Kallberg, ECMWF, 2000, personal communication) and Amundsen-Scott (D. Bromwich, Byrd Polar Research Center, 2000, personal communication). Unfortunately the AUST data only exist until the end of 1993 (when a new scheme started) and the UKMO data were only available to the author from 1992 to 1996.

There were no significant changes in either operational analysis scheme during these time periods. Despite the shortness of the AUST (UKMO) data after (before) the 1993 feature, it is clear from Fig. 7 that neither the AUST or UKMO data demonstrate a similar drop in geopotential height. Since the feature is observed in many stations operated by different nations and is not apparent in data from other analyses, it is a problem unique to the NPR. The cause will be related to changes in the nature of regional data available to the NNR and how the assimilation scheme handles such changes.

Prior to 1993 the NNR was one of many meteoro- 


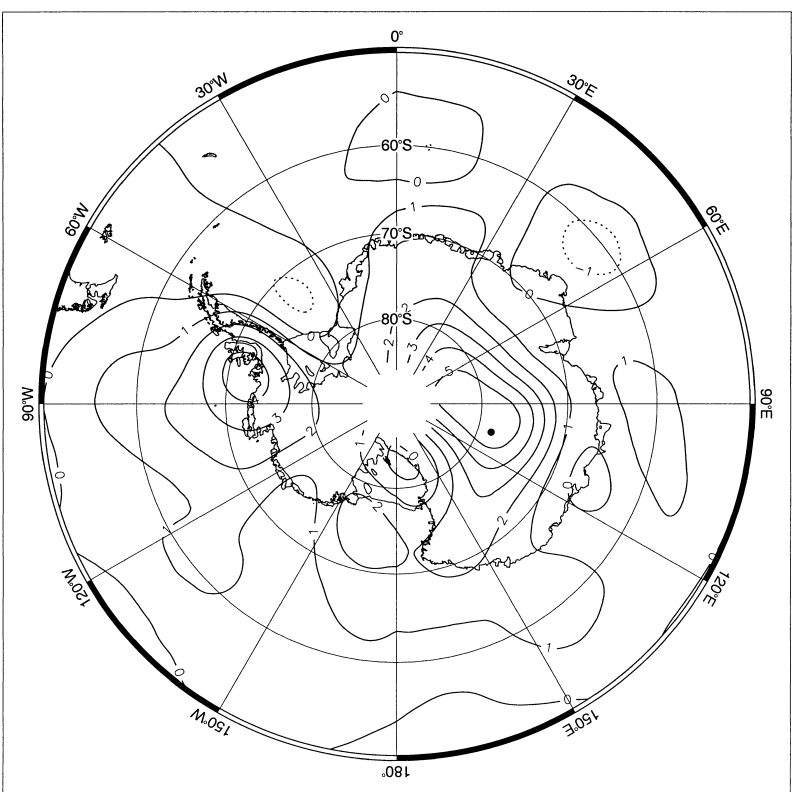

FIG. 8. The difference between the NNR and AUST analyses in 1992 minus that in 1991. Units are in dm. The position of Vostok station is shown as a black dot. Due to difficulties in interpolating the different grids used by the two analyses at $90^{\circ} \mathrm{S}$, data are only shown as far south as $85^{\circ} \mathrm{S}$.

logical analyses to have an error in the elevation of Vostok (Connolley and Harangozo 2001). This is clearly seen in Fig. 7, where typically the 500-hPa geopotential height in the NNR at Vostok is $5 \mathrm{dm}$ less than that of the radiosonde observations: the AUST data are much better, typically $1 \mathrm{dm}$ too high. Upper-air observations from Vostok ceased in January 1992; this can be clearly discerned in Fig. 8, which shows the difference in 500$\mathrm{hPa}$ geopotential heights between NNR and AUST in 1992 less that in 1991. Assuming that the AUST data are reasonably close to reality in this region, based on Fig. 7 and Table 4 of Connolley and Harangozo (2001), the large positive region over East Antarctica is indicative of the significant improvement in the NNR data between 1991 and 1992 in a positive direction. Note that the position of Vostok is marked in Fig. 8 and lies within the area of biggest change $(>5 \mathrm{dm})$, which is of a similar magnitude to that of the mean difference between the NNR and radiosonde observations at this station while the latter were available (Fig. 7). Figure 8 demonstrates that the Vostok height problem was not a contributing factor in the creation of the 1993 feature.

The spatial extent of the 1993 feature can be observed in Fig. 9, which shows the difference in 500-hPa geopotential heights between NNR and AUST in 1993 less that in 1992. In the coastal region of East Antarctica, the area of negative change extends from $30^{\circ}$ to $135^{\circ} \mathrm{E}$ and inland to approximately $76^{\circ} \mathrm{S}$. Note that the point of maximum negative change in this region is situated close to Mirny (cf. Fig. 1). Russian sources confirm that station observations were undertaken using identical

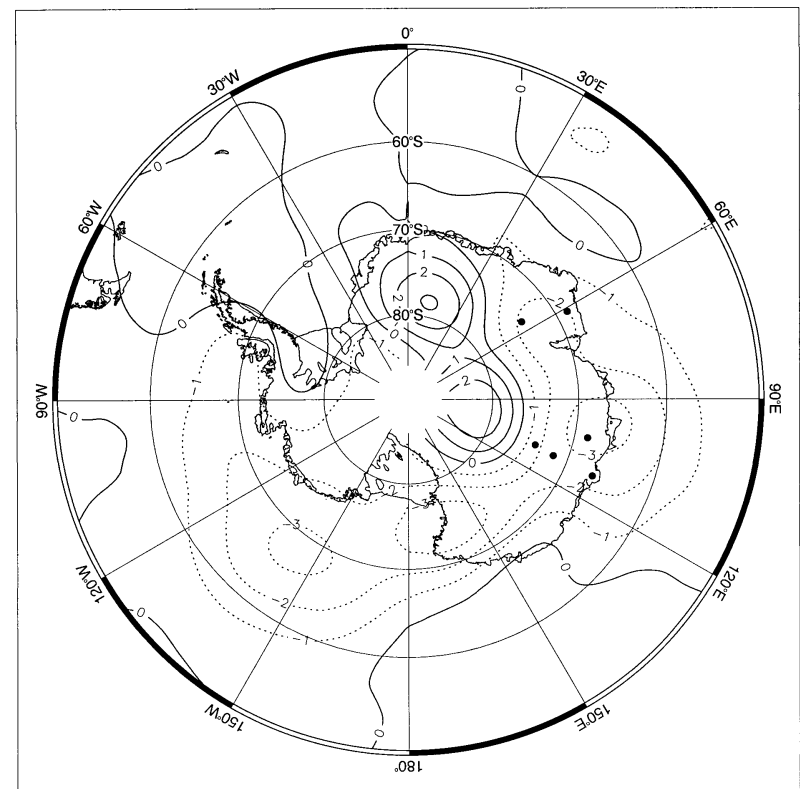

FIG. 9. The difference between the NNR and AUST analyses in 1993 minus that in 1992. Units are in dm. The positions of the six Australian AWSs that began operation in 1993 are shown as black dots.

procedures and equipment in 1992 and 1993 (V. Lagun, Arctic and Antarctic Research Institute, 2000, personal communication) and Fig. 7 gives no indication of a marked change in the difference between Mirny radiosonde observations and either AUST or UKMO 500$\mathrm{hPa}$ geopotential heights between these two years.

A check of the radiosonde observations available to the NNR over East Antarctica also showed no significant changes between 1992 and 1993. However, surface observations increased significantly in mid-1993, with the introduction of six Australian automatic weather stations (AWSs) at the very end of May 1993. The number of monthly observations from these AWSs available to the NNR between 1990 and 1997 is shown in Fig. 10, and their locations marked in Fig. 9. Note that WMO 89803 is located near the point of the maximum negative change between 1992 and $1993\left(68.5^{\circ} \mathrm{S}, 102.2^{\circ} \mathrm{E}\right)$. All but one of the others are situated in an area indicating a change of at least $2 \mathrm{dm}$; indeed, the two close to the $60^{\circ} \mathrm{E}$ meridian (WMO 89757 and 89762) appear to define the $-2-\mathrm{dm}$ contour. These AWSs are all positioned at relatively high elevations, ranging from 1366 to 3056 $\mathrm{m}$ above sea level, so their surface pressure observations will impact the reanalysis geopotential height fields. The hypothesis that the assimilation of data from one or more of these stations cause the 1993 feature is given credence by careful analysis of Figs. $4 \mathrm{a}-\mathrm{c}$ and Fig. 7 that show that the marked decline in NNR geopotential height occurs most significantly between May and June 1993. One observation was available in May from only two of the AWSs so their full impact would not have been felt until June. Comparing Figs. 7 and 10 also reveals 


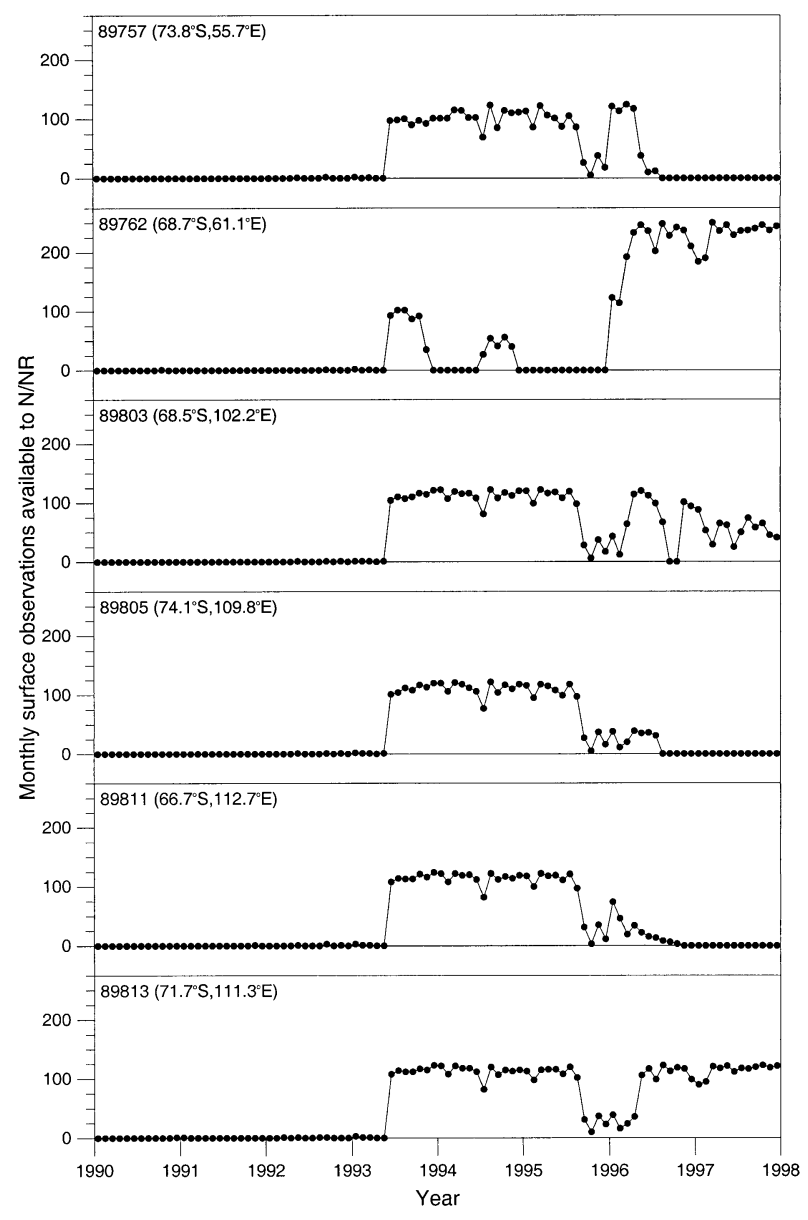

FIG. 10. Monthly surface observations available to the NNR from six Australian AWSs between 1990 and 1997.

that when the number of observations from the AWS situated close to the point of the maximum negative change in Fig. 9 (WMO 89803) declined in late 1995 then at Mirny the NNR actually had a 500-hPa geopotential height greater than that of the radiosonde data. Furthermore, it may also be argued that the demise of three of the AWSs in mid-1996 contributed to the gradual return of the NNR data to pre-1993 values; for example, the AWS located at Law Dome (WMO 89811) near Casey was one of these and mid-1996 is when the NNR values at this station began to improve consistently.

The 1993 feature probably results because the heights used for some of the AWSs in the model are significantly too low. This is certainly the case in the UKMO data; for example, the actual height of WMO 89803 is 2123 $\mathrm{m}$ whereas the model height was $2043 \mathrm{~m}$ in 1995; during January-June 1995 the mean difference between observation and model was $-9.5 \mathrm{hPa}$ (B. Ingleby, UKMO, 2000, personal communication). In both the NNR and UKMO schemes the surface pressure observations are extrapolated-interpolated to the surface pressure of the model topography (W. Ebisuzaki, NCEP, 1995, personal communication; Ingleby 1995). Yet the 1993 feature does not exist in the UKMO data; Ingleby (1995) stated that the problems caused by station height errors are mitigated by both quality control and data density. Over the Antarctic Plateau the former is obviously of far greater practical importance. In the UKMO analysis the quality control includes a background check that flags differences from background larger than $7 \mathrm{hPa}$ (Ingleby 1995). Available UKMO rejection lists begin in September 1994, and demonstrate that for the first 12 months of this archive AWSs WMO 89757, 89762, and 89805 were consistently rejected and WMO 89811 was rejected some of the time. It is believed that the fact that WMO 89803 does not appear on the list is simply because a necessary criteria for inclusion-receiving more than 30 reports over a 3-month period-was not met; however, the large bias of $9.5 \mathrm{hPa}$ means that most of the individual observations from this AWS would have been rejected (C. Parrett, UKMO, 2000, personal communication). From this investigation it appears that over data-sparse East Antarctica the UKMO uses a more appropriate methodology than the complex quality control system used in the NNR. It is not clear why the AWS data were given at least an equal weighting to the radiosonde observations, allowing the errors to be propagated upward to at least $100 \mathrm{hPa}$ in the NNR geopotential height fields (cf. Fig. 4d).

\section{Conclusions}

In this study we have undertaken a detailed analysis of 40-yr (1960-99) NNR upper-air trends in geopotential height and temperature at four levels at high southern latitudes. The NNR data have been compared to observational trends from Antarctica, represented by quality controlled radiosonde datasets from four Antarctic stations, three in East Antarctica, and one from the Weddell Sea coast. Differences between the trends derived from the two datasets have been examined in terms of changes in data availability, the NNR assimilation scheme, and model physics.

With a single exception, statistically significant trends in geopotential height from Antarctic radiosonde observations are limited to the lower stratosphere (100 $\mathrm{hPa}$ ). Here there has been a fall in height over East Antarctica. In the troposphere the NNR shows significant negative trends in geopotential height at high southern latitudes, due to a large positive bias in the reanalysis in the 1960s and a smaller negative bias in the 1990s. At $100 \mathrm{hPa}$ the NNR trends are an order of magnitude less than the observations, because of a large and generally negative height bias prior to the introduction of satellite sounder data in the mid-1970s.

Very good agreement exists between the two datasets regarding lower-tropospheric (850-500 hPa) temperatures trends, both in terms of magnitude and statistical significance. At $850 \mathrm{hPa}$ there has been a significant warming at Casey and Halley-the latter equivalent to 
a $1.4^{\circ} \mathrm{C}$ rise over the $40 \mathrm{yr}$ - while at $500 \mathrm{hPa}$ the warming above Mawson is also significant. At $850 \mathrm{hPa}$ a marked annual cycle in the difference between NNR and observations is apparent, probably related to errors in the surface energy balance model employed in the reanalysis. Mawson is the only station to demonstrate a significant warming in the radiosonde data at $300 \mathrm{hPa}$, but the NNR indicates such a trend at all four stations, again due to a jump to a more positive temperature bias at this level in the reanalysis, coincident with the assimilation of satellite sounder data. All four radiosonde time series exhibit a statistically significant cooling at $100 \mathrm{hPa}$, which at two stations exceeds $1^{\circ} \mathrm{C}$ decade ${ }^{-1}$ while the NNR displays a mix of both positive and negative trends. In addition to problems prior to the advent of satellite data, the NNR fails to account for the cooling in the austral spring (October and November) from the mid-1980s onward that occurs in response to seasonal Antarctic ozone loss.

A detailed examination of a rapid decline in NNR geopotential height in 1993 revealed unexpected problems associated with subtle changes in data availability. The marked decrease in geopotential height, widespread across much of East Antarctica and of the order of 5 $\mathrm{hPa}$ at $500 \mathrm{hPa}$ at Casey, was caused by the introduction of new AWSs in the region. The climate jump probably originated from deviations between the actual station and model heights for several of these AWSs, and indicates that the quality control methodology utilized by the NNR does not work effectively in the data-sparse region of East Antarctica. This is something that can and should be addressed in future NCEP-NCAR reanalyses.

Spurious climate jumps in reanalyses caused by changes in the type and spatial distribution of data will always be worse where the network of conventional data is limited; across Antarctica these jumps are sufficient to make reanalyses unsuitable for studies of long-term climate change detection. However, they are potentially better suited to providing a consistent upper-air climate dataset since 1979, when TOVS sounder data became available (Randel et al. 2000). Unfortunately the investigation of the 1993 feature reveals that the NNR cannot really be used with confidence even over this shorter time period. This regional finding corresponds closely with the more general view of Santer et al. (1999) who state "The discontinuities identified ... seriously diminish the usefulness of the NCEP data (NNR) for any climate change studies ...," and, in all fairness, a conclusion reached by NCEP workers themselves (Kistler et al. 2001). This study has therefore also further emphasized the unique role of radiosonde data for use in longer-term studies of changes in the properties of the Antarctic atmosphere. Yet several countries have reduced the scale of their presence in Antarctica, and at present there are only 11 stations undertaking routine radiosonde flights in the continent whereas in the past there have been as many as 17 . It is to be hoped that all current upper-air programs continue and the trend toward a reduced network is halted, in order that continuations of these important time series will be available into the future.

Acknowledgments. The author thanks the following people who have contributed to this study: Steve Colwell, William Connolley, Wesley Ebisuzaki, Terry Hart, Bruce Ingleby, Tom Lachlan-Cope, Colin Parrett, Howard Roscoe, Jack Woollen, and an anonymous referee.

\section{REFERENCES}

Angell, J. K., 1988: Variations and trends in tropospheric and stratospheric global temperatures, 1958-87. J. Climate, 1, 1296-1313.

Barnett, T. P., and M. E. Schlesinger, 1987: Detecting changes in global climate induced by greenhouse gases. J. Geophys. Res., 92, $14772-14780$.

Basist, A. N., and M. Chelliah, 1997: Comparison of tropospheric temperatures derived from the NCEP/NCAR reanalysis, NCEP operational analysis, and the Microwave Sounding Unit. Bull. Amer. Meteor. Soc., 78, 1431-1447.

Bromwich, D. H., A. N. Rogers, P. Kållberg, R. I. Cullather, J. W. V. White, and K. J. Kreutz, 2000: ECMWF analyses and reanalyses depiction of ENSO signal in Antarctic precipitation. $J$. Climate, 13, 1406-1420.

Christy, J. R., 1995: Temperature above the surface layer. Climatic Change, 31, 455-474.

Connolley, W. M., and S. A. Harangozo, 2001: A comparison of five numerical weather prediction analysis climatologies in southern high latitudes. J. Climate, 14, 30-44.

Cullather, R. I., D. H. Bromwich, and R. W. Grumbine, 1997: Validation of operational numerical analyses in Antarctic latitudes. J. Geophys. Res., 102, 13 761-13 784.

Dickson, B., 1999: All change in the Arctic. Nature, 397, 389-391.

Forster, P. M., de F., and K. P. Shine, 1999: Stratospheric water vapour changes as a possible contributor to observed stratospheric cooling. Geophys. Res. Lett., 26, 3309-3312.

Gaffen, D. J., 1994: Temporal inhomogeneities in radiosonde temperature records. J. Geophys. Res., 99, 3667-3676.

, 1998: Falling satellites, rising temperatures? Nature, 394, 615616.

_- M. A. Sargent, R. E. Habermann, and J. R. Lanzante, 2000: Sensitivity of tropospheric and stratospheric temperature trends to radiosonde data quality. J. Climate, 13, 1776-1796.

Hines, K. M., R. W. Grumbine, D. H. Bromwich, and R. I. Cullather, 1999: Surface energy balance of the NCEP MRF and NCEPNCAR reanalysis in Antarctic latitudes during FROST. Wea. Forecasting, 14, 851-866.

—_, D. H. Bromwich, and G. J. Marshall, 2000: Artificial surface pressure trends in the NCEP-NCAR reanalysis over the Southern Ocean and Antarctica. J. Climate, 13, 3940-3952.

Hurrell, J. W., and K. E. Trenberth, 1998: Difficulties in obtaining reliable temperature trends: Reconciling the surface and satellite microwave sounding unit records. J. Climate, 11, 945-967.

Ingleby, N. B., 1995: Assimilation of station level pressure and errors in station height. Wea. Forecasting, 10, 172-182.

Jenne, R., 2000: Global observations for reanalysis, 1948-on. Proc. Second WCRP Int. Conf. on Reanalyses, Wokefield Park, United Kingdom, WMO, 5-8.

Jones, A. E., and J. D. Shanklin, 1995: Continued decline of total ozone over Halley, Antarctica, since 1985. Nature, 376, 409411.

Kahl, J. D., M. Jansen, and M. A. Pulrang, 2001: Fifty-year record of north polar temperatures shows warming. Eos, Trans. Amer. Geophys. Union, 82, 1, 5.

Kalnay, E., and Coauthors, 1996: The NCEP/NCAR 40-Year Reanalysis Project. Bull. Amer. Meteor. Soc., 77, 437-441. 
Kistler, R., and E. Kalnay, 2000: The NCEP/NCAR reanalysis prior to 1958. Proc. Second WCRP Int. Conf. on Reanalyses, Wokefield Park, United Kingdom, WMO, 27-35.

— , and Coauthors, 2001: The NCEP-NCAR 50-Year Reanalysis: Monthly means CD-ROM and documentation. Bull. Amer. Meteor. Soc., 82, 247-267.

Lanzante, J. R., 1996: Resistant, robust and non-parametric techniques for the analysis of climate data: Theory and examples, including applications to historical radiosonde station data. Int J. Climatol., 16, 1197-1226.

, 1998: Correction. Int. J. Climatol., 18, 235.

Luers, J. K., and R. E. Eskridge, 1998: Use of radiosonde temperature data in climate studies. J. Climate, 11, 1002-1019.

Marshall, G. J., and S. A. Harangozo, 2000: An appraisal of NCEP/ NCAR reanalysis MSLP data viability for climate studies in the South Pacific. Geophys. Res. Lett., 27, 3057-3060.

Met Office, 1979: Handbook of Weather Messages Part III Coding. 6 ed. Her Majesty's Stationary Office, 136 pp.

Mo, K. C., X. L. Wang, R. Kistler, M. Kanamitsu, and E. Kalnay, 1995: Impact of satellite data on the CDAS-Reanalysis system. Mon. Wea. Rev., 123, 124-139.

Nash, J., and F. J. Schmidlin, 1987: WMO international radiosonde comparison (U.K. 1984, USA 1985). WMO Instruments and Observing Methods Final Rep. 30, WMO, Geneva, Switzerland, $103 \mathrm{pp}$.

Oort, A. H., and H. Liu, 1993: Upper-air temperature trends over the globe, 1958-1989. J. Climate, 6, 292-307.

Parish, T. R., 1988: Surface winds over the Antarctic continent: A review. Rev. Geophys., 26, 169-180.

Parker, D. E., and D. I. Cox, 1995: Towards a consistent global rawinsonde data-base. Int. J. Climatol., 15, 473-496.

—, M. Gordon, D. P. N. Cullum, D. M. H. Sexton, C. K. Folland, and N. Rayner, 1997: A new global gridded radiosonde temperature data base and recent temperature trends. Geophys. Res. Lett., 24, 1499-1502.

Ramaswamy, V., M. D. Schwarzkopf, and W. J. Randel, 1996: Fingerprint of ozone depletion in the spatial and temporal pattern of stratospheric cooling. Nature, 382, 616-618.

Randel, W. J., and F. Wu, 1999: Cooling of the Arctic and Antarctic polar stratospheres due to ozone depletion. J. Climate, 12, 1467 1479.

- - - and D. J. Gaffen, 2000: Interannual variability of the tropical tropopause derived from radiosonde data and NCEP reanalyses. J. Geophys. Res., 105, 15 509-15 523.

Santer, B. D., and Coauthors, 1996: A search for human influences on the thermal structure of the atmosphere. Nature, 382, 39-46.

, J. J. Hnilo, T. M. L. Wigley, J. S. Boyle, C. Dourtriaux, M. Fiorino, D. E. Parker, and K. E. Taylor, 1999: Uncertainties in observationally based estimates of temperature change in the free atmosphere. J. Geophys. Res., 104, 6305-6333.

Shah, K. P., and D. Rind, 1998: Comparing upper tropospheric and lower stratospheric temperatures: Microwave sounding unit, radiosonde, COSPAR International Reference Atmosphere, and National Center for Environmental Prediction/National Center for Atmospheric Research reanalysis monthly mean climatologies. J. Geophys. Res., 103, 31 569-31 591.

Smith, R. C., S. E. Stammerjohn, and K. S. Baker, 1996: Surface air temperature variations in the western Antarctic Peninsula region. Antarct. Res. Ser., 70, 105-121.

Tett, S. F. B., J. F. B. Mitchell, D. E. Parker, and M. R. Allen, 1996: Human influence on the atmospheric vertical temperature structure: Detection and observations. Science, 274, 1170-1173.

Thompson, D. W. J., and J. M. Wallace, 2000: Annular modes in the extratropical circulation. Part I: Month-to-month variability. $J$. Climate, 13, 1000-1016.

Trenberth, K. E., 1984: Signal versus noise in the Southern Oscillation. Mon. Wea. Rev., 112, 326-332.

Uppala, S., J. K. Gibson, M. Fiorino, A. Hernandez, P. Kållberg, X. Li, K. Onogi, and S. Saarinen, 2000: ECMWF second generation reanalysis-ERA40. Proc. Second WCRP Int. Conf. on Reanalyses, Wokefield Park, United Kingdom, WMO, 9-13.

von Storch, H., and F. W. Zwiers, 1999: Statistical Analysis in Climate Research. Cambridge University Press, $484 \mathrm{pp}$.

Wallis, T. W. R., 1998: A subset of core stations from the Comprehensive Aerological Reference Dataset (CARDS). J. Climate, 11, 272-282.

Wentz, F. J., and M. Schabel, 1998: Effects of orbital decay on satellite-derived lower-tropospheric temperature trends. Nature, 394, 661-664. 